\title{
ORQUÍDEAS DEL VALLE ESCONDIDO
}

\author{
Jorge Arturo CAMPos \\ Reserva Valle Escondido, San Lorenzo de San Ramón, Costa Rica
}

Perfil de la Reserva Valle Escondido. La Reserva Valle Escondido se encuentra ubicada a sólo $90 \mathrm{~km}$ de la ciudad de San José, camino a la Fortuna Volcán Arenal, exactamente a $32 \mathrm{~km}$ de la ciudad de San Ramón de Alajuela. Tiene un área aproximada de 120 hectáreas, cubiertas en su mayoría por bosque secundario maduro y parches de bosque primario del tipo premontano húmedo. El ámbito altitudinal de la reserva varía entre $300 \mathrm{~m}$ s.n.m. en las riberas del Río Balsa y $550 \mathrm{~m}$ en las partes más altas. La topografía es variada, con abundantes fuentes de agua, entre las que destaca el Río Balsa. Por su ubicación, la reserva es afectada por las situaciones climáticas del atlántico. En consecuencia su clima es variado y poco determinado, nuboso, lluvioso o soleado, con intervalos inesperados y con una humedad relativa normalmente muy elevada. Actualmente hay allí un proyecto ecoturístico, que permite durante todo el año a los amantes del turismo ecológico disfrutar de la rica biodiversidad de la reserva: observación de aves, mamíferos y diferentes especies de plantas.

Flórula de orquídeas de la Reserva Valle Escondido. En el año 1991 se creó esta reserva privada, con el fin de conservar 120 hectáreas ubicadas en San Lorenzo de San Ramón. El proyecto "Flórula de orquídeas de la Reserva Valle Escondido" se inició en el año 2000 con la idea de cuantificar, estudiar y proteger las especies de orquídeas de la reserva.

\section{Metodología.}

a) Ubicación de un área determinada para ser sometida a estudio. Para este fin se seleccionaron las 120 hectáreas de bosque primario y secundario ubicadas en las márgenes del Río Balsa, San Lorenzo, San Ramón de Alajuela, donde se ubica un proyecto de turismo ecológico, el Hotel Valle Escondido.

b) Trabajo de campo. Incluye la observación y anotación de datos relativos a las especies de orquídeas en su estado natural. c) Libro de campo. Las colectas son debidamente registradas tomando en cuenta:

- nombre de la especie

- ubicación geográfica

- altitud sobre el nivel del mar

- fecha de recolecta

- número de plantas recolectadas (máximo dos plantas por especie

- observaciones hechas en el momento de la recolecta (ej. floración, producción de frutos, etc.)

d) Mantenimiento de testigos vivos. Las plantas recolectadas se mantienen en un invernadero diseñado para tal uso, para poder seguir siendo estudiadas.

e) Producción de ilustraciones científicas. Estas incluyen:

- acuarelas de la planta en floración

- dibujo a plumilla con el hábito de la planta y el desglose de cada una de las partes de la flor

f) Preparación de material de referencia en alcohol.

Resultados. Después de 2 años de trabajo, se han determinado en la Reserva 172 especies de orquídeas en 50 géneros (Tabla 1). La colección de ilustraciones, que incluye dibujos a plumilla y acuarelas, cuenta con un número importante de láminas. En el invernadero del Valle Escondido se mantienen en cultivo como testigos vivos las especies recolectadas con el fin de continuar las investigaciones y atender grupos y personas interesadas, a las cuales se proporcionan charlas e información sobre la flora de orquídeas de la zona. Se mantiene además una cantidad importante de material de referencia en alcohol. El proyecto se ha dado a conocer mediante la participación en foros internacionales y la publicación de artículos en revistas (Pupulin 2002), y ha tenido aceptación y apoyo por parte de personas e instituciones rela- 
Tabla 1. Número de especies por género de orquídeas encontradas en la Reserva Valle Escondido.

Maxillaria

Epidendrum

Pleurothallis s.l.

Gongora

Scaphyglottis

Stelis

Dichaea

Sobralia

Prosthechea

Oncidium

Brassia

Kefersteinia

Lockhartia

Trichopilia

Xylobium

Elleanthus

Cryptocentrum Jacquiniella

Mormodes

Restrepia

Sarcoglottis

Sigmatostalix

Stanhopea

Acrorchis

Arpophyllum

Aspasia

Catasetum

Campylocentrum

Cryptarrhena

Cyclopogon

Deiregyne [?]

Dimerandra

Huntleya

Lycaste

Mesospinidium

Myoxanthus

Nidema

Notylia

Ornithocephalus

Palmorchis

Platystele

Polystachya

Prescottia

Sacoila

Scaphosepalum

Systeloglossum

Ticoglossum

Trichocentrum

Trichosalpinx

Trigonidium

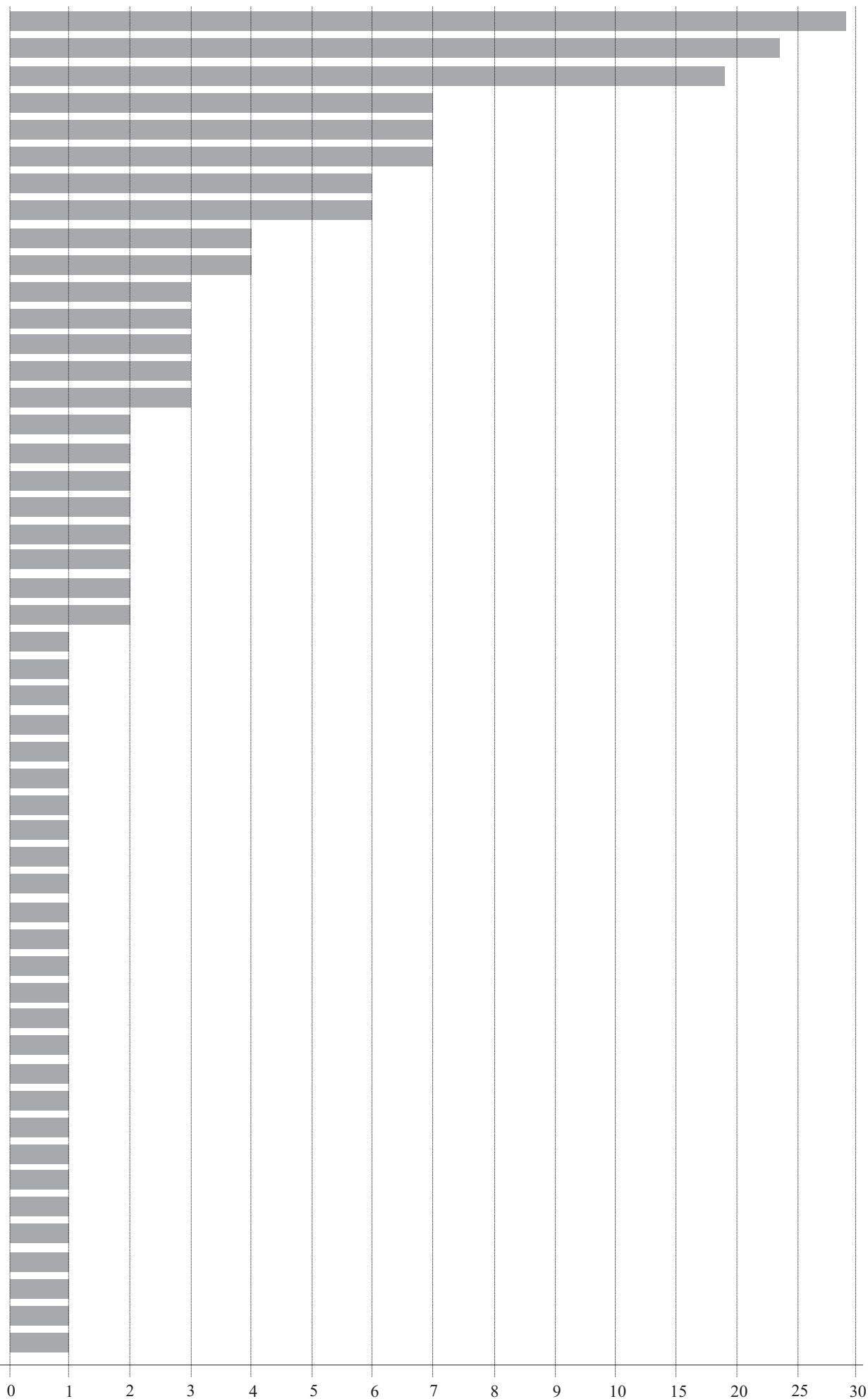


cionadas con el estudio y la conservación de las especies de orquídeas de Costa Rica.

Proyecciones del proyecto. Además de continuar con la recolecta y la identificación de especies aún no incluidas en el listado preliminar, las actividades del proyecto pretenden para el futuro:

- establecer datos de frecuencia de las especies que permitirán evaluar con precisión su estado de conservación

- realizar una publicación del estudio realizado en la Reserva Valle Escondido.

\section{Literatura CitAda}

Pupulin, F. 2002. En el Valle Escondido las orquídeas se revelan. Epidendrum 16: 3.

Jorge Arturo Campos nació en 1961 en San Ramón, Alajuela, Costa Rica. Se ha dedicado desde muy joven al manejo, cultivo y exportación de plantas ornamentales y al desarrollo de una carrera artística como pintor. Ambas actividades le dan la afinidad necesaria para el interés que desde muy joven tiene en las orquídeas costarricenses. Desde los 17 años comenzó a hacer trabajos de campo, visitando diferentes zonas del país y haciendo observaciones de las diferentes orquídeas. Ha trabajado en ilustración de muchas de las especies costarricenses y colaborado con la Asociación Ramonense de Orquideología. Actualamente se dedica al estudio e ilustración de las orquídeas presentes en la Reserva Valle Escondido. 